\title{
İnsan Hakları Bağlamında Özel Hayatın Gizliliği Ve Korunması
}

\author{
Ali KORKMAZ \\ Erciyes Üniversitesi İletişim Fakültesi
}

\begin{abstract}
Özet
Herkes, özel hayatına ve aile hayatına saygı gösterilmesini isteme hakkına sahiptir. Özel hayatın ve aile hayatının gizliliğine dokunulamaz' (Anayasa 20. md.). Bu hak, Anayasa ile de güvence altına alınmıştır. Son yıllarda teknolojinin gelişmesiyle birlikte özel hayata dâhil olan alanların boyutları da genişlemiștir. Kișinin, özel hayatı ve aile hayatı yanında, konutuna, haberleșmesine, kamusal ve sanal alanlardaki haklarına da saygı gösterilmelidir. Özel hayatın gizliliği bir insan hakkıdır ve ihlali durumunda suç teşkil eder. Milli güvenlik, kamu düzeni, genel sağlık, genel ahlak, ülkenin ekonomik refahı, suç işlenmesinin önlenmesi, başkalarının hak ve özgürlükleri, dirlik ve düzenin korunması gibi durumlarda özel hayata müdahale olabilir. Ancak bu müdahale, yasayla belirlenmiş olmak koşuluyla ve bir kamu otoritesinin izniyle gerçekleșebilir. Yasalara dayanmayan ve bir izne tabii olmayan müdahaleler, özel hayatın gizliliğine müdahaledir ve suç teşkil eder. Makale, literatür taramasına dayalı niteliksel bir çalışmadır. Çalışmada, özel hayatın gizliliği ve korunması bir insan hakkı olarak ele alınmıștır.

Anahtar Kelimeler: Özel Hayat, Mahremiyet, Gizlilik, Aile Hayatı, Medya.
\end{abstract}

\section{The Right and Protection of Privacy in the Context of Human Rights}

\begin{abstract}
Everyone has the right to respect for his private and family life. Inviolable privacy of a private and family life '(Article 20 of the Constitution.). This right is guaranteed by the Constitution. With the development of technology in recent years has expanded the dimensions of the fields that are included in private life. The person next to her private life and family life, home, correspondence, public and respect the rights of sandboxes. If privacy is a human right and a violation of criminal offenses. National security, public order, public health, public morality, the country's economic well-being, the prevention of crime, the rights and freedoms of others, is peace and order, the protection of private life can interfere in such cases. However, this interference by a public authority and permission of the condition to be determined by the law occur. Interventions based on the law and not subject to authorization, confidentiality of private life and an offense to the intervention. The article is based on a qualitative study of literature. In the study, protection of privacy and is considered as a human right.
\end{abstract}

Keywords: Private Life, Privacy, Privacy, Family Life, Media.

\section{Giriş}

İnsan toplumsal bir varlıktır. İlk çağlardan beri insanlar topluluklar halinde yaşamıştır. Toplum içinde yaşayan insanın aynı zamanda, diğer insanlarla paylaşmadığı, kendine ait özel ve mahrem hayatı da mevcuttur. Kişinin sadece kendisinin belirlediği kişilere açtığı, bilinmesini istemediği ve korunmasını istediği bu hayata, özel hayat denilmektedir. Her insan, özel ve mahrem hayatına saygı gösterilmesini isteme hakkına sahiptir. Bu hak yasalarca da güvence altına alınmıştır. İnsan kişiliğinin sağlıklı gelişmesi için başkalarının denetiminden ve gözetiminden uzak, özgürce yaşayacağı hayata da ihtiyacı vardır.

Özel hayat, Avrupa İnsan Hakları Sözleşmesi (AİHS, 8. madde) ve İnsan Hakları Evrensel Bildirgesi (12. madde)'nde de yer almaktadır. Kişilik hakları içerisinde özel hayat, ayrı bir öneme sahiptir. Öyle bir haktır ki bu, kontrolü kişinin elindedir ve başkalarının müdahalesini istemediği bir hayattır. Temelinde özgürlük ve mahremiyet vardır. Özel hayat konusu, dini, felsefi, ideolojik, hukuki birçok alanda ele alınabilir. Çalışmada özel hayatın gizliliği ve korunması insan hakları bağlamında ele alınmıştır. Makalede bir insan hakkı olarak özel hayat konusu, Türk Anayasa'sında ve Avrupa Birliği yasaları 1şığında irdelenmiştir.

\section{2. İnsan Hakkı}

İnsan hakkı, insana sırf insan olduğu için tanınan bir takım haklardan oluşur. O yüzden, bu hakka dayanan taleplerin, diğer taleplere karşın bir önceliği vardır, insan hakları, bir başka deyişle tabii haklar, doğumla birlikte kazanılan, doğrudan doğruya kişinin şahsına bağlı haklardır. $\mathrm{Bu}$ haklar, bir başkasına devredilemez, üzerinde tasarruf yapılamaz ve bu haklardan feragat mümkün değildir. Yine, tabii hak kategorisine giren haklar, herkese karşı ileri sürülebilen haklardır. Özel hayata devlet tarafından müdahalede bulunulabilmesi için, yüksek kalitede garantiler öngören bir yasa mevcut bulunmalıdır. Devlet bu haklara saygı göstermek ve olağan gelişimini sağlamak üzere, fiili ve hukuki her türlü önlemi almak ve gerekli düzenlemeleri yapmakla mükelleftir. Aklı olan, düşünebilen ve eş zamanlı olarak psikolojik varlığı olan insanın sırf insan olması nedeniyle doğuştan bazı haklarının var olduğu savı insan hakları düşüncesinin başlangıcı olmuştur (Aras, 2010: 3).

'İnsan Hakları', 'Kamu Özgürlükleri', 'Temel Haklar', 'Kişi Hakları ve Özgürlükleri' ve 'Kamusal Haklar' kavramları çoğu zaman birbirinin yerine kullanılan kavramlardır. İnsan Hakları, salt insan olmaları nedeniyle, her zaman, her koşulda 
ve her yerde sahip oldukları ve insana yaraşır bir yaşam ve insanın kendini gerçekleştirebilmesi için vazgeçilmez nitelikteki dinamik haklardır. Özel hayat hakkı, insan haklarını (temel haklar) koruma altına alan uluslararası belgelerde ve anayasalarda yer alır. Bunun temelinde özel hayat hakkının, bir insan hakkı olması kabul görür. Özel hayat hakkının insan hakları/temel haklar arasındaki yeri onun kural olarak dokunulmaz, vazgeçilmez, devredilemez nitelikte olduğuna ve ancak yasayla sınırlanabileceğine ve bu sınırlamanın da hakkın özüne dokunulmayacak şekilde yapılması gerektiğine işaret eder (Sevimli, 2006: 24-25).

\section{3. Özel Hayat Kavramı ve Kapsamı}

Özel hayat, Türk Dil Kurumu'nun Türkçe Sözlüğü'nde şu şekilde tanımlanmaktadır; 'kişinin kendine özgü yaşayışı, yaşama tarzı, kendisini ilgilendiren tutum ve davranışlar' (TDK Türkçe Sözlük, 2005: 155). Bir başka tanıma göre ise; 'kişilerin hukuken korunan, herkesle paylaşmadiğı ve güvendiği kişiler dışında herkesten gizli tuttuğu yaşam alanıdır' (Kılıçoğlu, 2008: 112). Özel hayatın gizliliği ve korunması konusunda birçok tanım yapılmaktadır; 'Kişinin sadece kendisi için saklı tuttuğu ve başkalarının bilgisinden uzak kalmasını istediği yaşam görünümleri', 'Herkes tarafından bilinmeyen, özel araştırma ve bilgi edinmeyle sağlanan kişiye ait hususlar', 'Kişilerin gizli hayat alanlarında yapmış oldukları faaliyetlerin başkaları tarafından bilinmemesini istedikleri taraflar', 'Özel yaşamın düzenini ve bu yaşama kimlerin, ne ölçüde, nasıl ve ne zaman müdahale edebileceklerini veya bu yaşamı algılayabileceklerini bireyin kendi kendisine saptaması' ya da 'Başkalarının, bireyin özel yaşamını onun koyduğu ölçüler içerisinde algılayabilmesi veya bu yaşama müdahale edebilmesi' şeklinde tanımlanabilmektedir. Kişilerin hayat çevreleri 4 şekilde oluşmaktadır (Şen, 1996: 5-6);

1-Kişinin kamusal hayatı

2-Kişinin mesleki hayatı

3-Kişinin aile hayatı

4-kişinin özel hayatı

Özel hayat kavramı ile ilgili terim farklılıkları, daha ziyade kişinin özel hayatını koruma altına alan temel hakkını ifade edilmesi ile ilgilidir. Gerçekten de, bu hakkı ifade etmek üzere, 'özel hayat hakkı', 'özel hayatın gizliliği hakkı', 'mahremiyet hakkı', 'özel hayatın korunması ve gizliliği hakk1, 'özel hayata saygı gösterilmesi hakkı', 'özel hayata ve aile hayatına saygı gösterilmesi hakkı', 'özel hayata, aile hayatına, konut ve haberleşme özgürlüğüne sayı hakkı' gibi terimler kullanılmaktadır. Özel hayat terimi gerek yalnızca gizlilik ekseninde korunan yaşam alanını diğer bir deyişle mahrem alanı, tüm müdahalelere karşı korunan yaşam alanını ifade etmek üzere kullanılabilmektedir. Bu durumun özel hayatın tanımlanma ve sınırlanma çabalarını olumsuz etkileyeceği aşikârdır. Nitekim bu sakıncaları gidermek için gizlilik bağlamında korunan yaşam alanını ifade etmek üzere 'özel (bireysel) hayat' tabiri kullanılmıştır (Keklik, 2012: 89).

Özel hayatın sınırları, kişinin izinsiz girilmeyecek, teşhir edilemeyecek ve ticari metaya dönüştürülmeyecek alanlarını kapsamaktadır. Ülkeden ülkeye bazı farklılıklar olmakla beraber çoğu ülkede bu kapsama giren konuları şöyle sıralayabiliriz; kişinin özel notları, fotoğrafları, mektup veya günlükleri, cinsel yaşamı, sağlı̆̆ına ilişkin bilgiler, özel yaşamını geçirdiği mekânlar, aile ilişkileri vb. (İşçibaşı: 2011: 167)

\section{1. Özel Hayat Kavramının Tarihsel Gelişimi}

Eski Roma ve Yunan uygarlıklarında özel hayatın gizliliğinden söz etmek olanaklı değildir. V. yüzyıldan itibaren özellikle de Batı Roma İmparatorluğu'nun yıkılıp dışarıdan gelen kavimlerin egemen duruma geçmesi ile birlikte feodaliteye giden süreç başlamıştır. Bunun sonucunda da kişilerin daha korunaklı evlerde, kulübelerde yaşamaya başlaması ile mahremiyet yeniden önem kazanmıştır. Konut dokunulmazlığı ve gönderilerin gizliliği ile özel hayatın gizliliği kısmen de olsa korunmuştur. İngiltere'de 1710 tarihli bir kanun ile gönderilerin karar olmaksızın açılması yasaklanmıştır. Özel hayat, 16. yüzyılda, sanayi toplumundaki gelişme, şehirleşmenin artması ve basının önem kazanması sonucunda daha ciddi ve yoğun biçimde tehdit edilir hale gelmiştir. Birey kavramının ön plana çıktığı 18 ve 19. yüzyılda özel hayatın korunmasına yönelik adımlar atılmıştır. Ad, şöhret veya mektuplar üzerindeki haklar yoluyla özel hayat korunmuştur. ABD'de özel hayatın gizliliği, özel hayata saygı hakkı gibi kavramların tartışılması 19. yüzyılın ikinci yarısında başlamıştır. Konunun dünya ölçeğinde gündeme gelmesi 20. yüzyılın ikinci yarısında olabilmiştir. 2. Dünya savaşının ardından temel haklar ve insan hakları anlayışının gelişmesi, teknolojideki çok hızlı değişim özel hayatın gizliliği hakkının daha ciddi korunması gerektiğini ortaya koymuştur (Akyürek, 2011: 105-108).

\section{4. Özel Hayatın Alt Unsurları}

Kişisel veriler, konut, haberleşme ve aile hayatına sayg1, geniş anlamda 'özel hayatın' alt unsurları olarak kabul edilmektedir. Aşağıda bu unsurlar ele alınacaktır.

\subsection{Kişisel Veriler}

Kişisel veri kavramı ile özel hayat kavramı arasında yakın bir ilişsi vardır. AİHM de kişisel verilerin toplanıp depolanmasını, sözleşmenin 8. maddesi kapsamına gireceğini kabul etmiştir. Kişisel veri kavramına, klasik anlamda özel hayat kavramının kapsamının dışına da taşacak bir anlam yüklenmesi söz konusudur. Öyle ki kişisel verilerin korunması, özel hayat dışındaki kişilik hakları ve mülkiyet hakkı ile de ilişkilendirilmektedir. Kişilerin adı, soyadı, telefon numarası, motorlu taşıt plakası, sosyal güvenlik numarası, pasaport numarası, özgeçmişi, resmi, sesi, parmak izleri, genetik bilgileri, sağlık durumuna ilişkin bilgileri, belli başlı kişisel verileri olarak kabul edilmektedir (Keklik, 2012: 25-28). Kişisel veriler Anayasa'nın 20. maddesinde güvence altına alınmıştır; 'Herkes kendisiyle ilgili kişisel verilerin korunmasını isteme hakkına sahiptir. $\mathrm{Bu}$ hak, kişinin kendisiyle ilgili kişisel veriler hakkında bilgilendirilme, bu verilere erişme, bunların düzeltilmesini veya silinmesini talep etme ve amaçları doğrultusunda kullanıp kullanılmadığını öğrenmeyi de kapsar. Kişisel veriler, ancak kanunda öngörülen hallerde veya kişinin açık rızasıyla işlenebilir. Kişisel verilerin korunmasına ilişkin esas ve usuller kanunla düzenlenir' (Anayasa 20. madde).

Avrupa Komisyonu, 1995 tarihli 'Veri Koruma Direktifi'nde reform yapılması için çalışmalar başlatmıştır. Akıllı telefonlar, bulut bilişim, konum servisleri ve sosyal medya ile veri kavramının modernleşmesi ve genişlemesi gerektiği düşüncesinden yola çıkan Birlik, hızlı teknolojik gelişmelere adapte olabilecek ve dijital çağın gereksinimlerini karşılayabilecek bir veri koruması reformu yapma düşüncesindedir. Avrupa Komisyonu, bireylerin haklarını 
güçlendirecek ve polis ile ceza adalet sistemi de dahil olmak üzere, her alanda, ileri seviye koruma temin edebilecek küresel nitelikte veri koruması standartları düzenlemeyi hedeflemektedir (Uğur, 2013: 28).

Kişisel verilerin kaydedilmesi, kullanılması kişinin izni olmazsa suçtur. Fransa'nın eski Cumhurbaşkanı François Mitterand'ın sağlık sırları bir gazetede yayınlanmıştır. Özel hayatın gizliliğini ihlal suçu kapsamında ailesi dava açarak yayın yasağı koydurtmuştur. Manoca Prensesi Caroline'nin çeşitli fotoğraflarının gazetelerde yayınlanması üzerine açtığı davada, prenses olsa dahi resmi bir görevinin olmadığı için fotoğrafların özel hayata müdahale olduğuna hükmetmiştir (24 Haziran 2004 tarihli-Von Hannover-Almanya kararı) (Akyürek, 2011: 123-124).

Kamusal verilerin toplatılması, kamusal alanda kamera takip sistemleri ile kaydetme, saklama, verileri iletme gibi unsurların varlığı, sağlı̆ga ve kişiliğe ilişkin gizli bilgiler, fiziksel durum, malvarlığının açıklanması özel hayata müdahaledir.

\subsection{Konuta Saygı Hakkı}

Kişinin, özel hayatını en yoğun yaşadığı yer olarak nitelendirilebilecek konutunun özel hayatın korunmasında ayrı bir yeri vardır. Dahası insanlığın modernleşme sürecine kadar özel hayat ihtiyacı, konut dokunulmazlığı ile sağlanmıştır. Konut dokunulmazlığı, AİHS (Avrupa İnsan Hakları Sözleşmesi) m.8'de, kişinin özel hayatı ile birlikte zikredilmiştir. Kişinin konutu, sadece gizlilik bağlamında özel hayatın bir alt unsuru olarak kabul edilemez. Haberleşmede olduğu gibi konutun gizliliğinin korunması mutlaka özel hayata dair bir olayın gizliliğinin korunması koşuluna bağlı değildir (Keklik, 2012: 24-25). Anayasa'nın 21. maddesinde 'Kimsenin konutuna dokunulamaz' hükmü yer almaktadır. Konut dokunulmazlığı sadece ev ile sınırlı değildir. Aynı zamanda işyeri, yazlık, otel odaları vb.de konuta saygı kapsamında değerlendirilmektedir.

\subsection{Haberleşme Hürriyeti (Haberleşme Hakkına Saygı)}

Haberleşme, kişiler arasında her türlü vasıta ile yapılan bilgi ve düşünce aktarımını ifade etmektedir. Haberleşme hürriyeti başta haberleşmenin engellenmesi olmak üzere haberleşmeye yönelik her türlü müdahaleyi reddetmesi yönüyle haberleşmenin gizliliğin sağlanmasından daha çok şey ifade etmektedir. Haberleşme hürriyetinin konusunu oluşturan ve tüm yönleriyle korunan haberleşme kavramı, geniş anlamda özel hayatın bir alt unsuru kabul edilmektedir. Haberleşmeye ilişkin düzenlemeler, genellikle haberleşmenin gizliliğinin korunması bakımından, haberleşmenin içeriği ile ilgilenmezler. Haberleşmenin gizliliğinin korunmasını öngörürler. Haberleşmenin korunmasına ilişkin düzenlemelerin sağladığı gizlilik koruması, özel hayata ilişkin düzenlemelerden daha geniştir. Bu nedenle gizlilik bağlamında haberleşmenin kapsamı, özel hayatın dışına taşmaktadır (Keklik, 2012: 22-23). Anayasa'da 'Herkes, haberleşme hürriyetine sahiptir. Haberleşmenin gizliliği esastır' maddesi yer alır (Anayasa 22.madde).

\subsection{Aile Hayatına Saygı}

Aile hayatının da özel hayat gibi başkalarının müdahalesinden korunması gerekir. Aile hayatının korunması, kişilerin ailevi ilişkilerini özgürce yaşayıp sürdürebilmelerini ifade eder. Aile hayatının gizliliğinin ihlal edilmesi, bunun sağlanmasını engelleyeceğinden aile hayatına bir müdahale teşkil eder. Dolayısıyla aile hayatının diğer müdahaleler yanında gizlilik ihlallerine karşı da korunması gerekir. Anayasamızın 20. maddesinde 'Özel hayatın ve aile hayatının gizliliğine dokunulmaz' ifadesi yer almaktadır. Bu ifade, aile hayatının gizlilik unsuru bağlamında özel hayat kapsamında kalmayan bir bölümünün bulunması ihtimalini gündeme getirmesi bakımından önemlidir (Keklik, 2012: 20-21).

\section{5. Özel Hayatın Gizliliği}

Özel hayat, bütün insan hakları içerisinde anlaşılması en zor alandır. Westin'e göre mahremiyet kişilerin, grupların veya kurumların kendilerine ait verilerin ne zaman, nasıl ve ne ölçüde diğerlerine aktarılabileceğini kendilerinin belirleme hakkıdır. Fisher-Hubber mahremiyetin üç niteliğe sahip olduğunu ifade eder: Mekânsal mahremiyet, kişi mahremiyeti ve veri mahremiyetidir. İlki, bireyi kuşatan yakın fiziksel alanı korumayı, ikincisi kişiyi haksız müdahalelere karşı korumayı, üçüncüsü de kişisel bilgilerin toplanma, saklanma ve dağıtımının nasıl yapılacağını veya yapılmayacağını kontrol etmeyi gerektirir. Mahremiyet kişi özgürlüğünün bir parçası olduğundan mahremiyetin ihlal edilmesi özgürlüğünün de ihlali sayılır (Karahisar, 2011: 602). Mahremiyet, insan gelişimi için önemlidir. İnsan Hakları Avrupa Komisyonu'nun ifadesine göre, 'özel hayata' saygı hakkı, mahremiyet hakkıdır, kişinin dilediği sürece aleniyetten korunarak yaşama hakkıdır. Özellikle de kişinin kendi kişiliğini geliştirmek ve gerçekleştirmek için, duygusal alanda olmak üzere, başka insanlarla ilişkiler kurmasını ve geliştirmesini de içerir. Filozof John Stuart Mill'de, insanların yaşamlarını tetkik ve müdahaleden korunarak yaşamalarına izin verilmesinin, insan gelişsimini teşvik edeceğini söylemektedir (Doyle-Bagarıc, 2007: 125). Mahremiyet hakkı, kişiler için yaşamsal önemi olan bir kavramdır (Kumcuoğlu, 2011: 56).

\section{1. Özel Hayata Saygı Hakkı}

İnsan sosyal bir varlık olarak daima başkalarıyla ilişki içindedir. Bu ilişkiler sonucu, insanlar başkaları tarafından görülmekte, izlenmekte, karşılıklı görüş ve düşünceler açıklamakta, olaylar başkaları tarafından duyulmaktadır. Bunun sonucu olarak, kişilerin yaşam olayları hakkında başkaları bilgi edinebilmektedir. $\mathrm{Bu}$ bilgilerin kapsamı, kişinin başkalarıyla olan ilişkisinin derecesine bağlıdır. Kişi, yaşamındaki birçok olayları ne zaman, kiminle, hangi ölçü içinde paylaşacağına bizzat karar verir. $\mathrm{Bu}$ olayların bir kısmını kendisine belirli yakınlıkta olan kişilerle birlikte yaşayabilir. Bu kişiler arasında, aile fertleri, arkadaş grupları, meslektaşlar sayılabilir. Buna karşılık, öyle bazı olaylar vardır ki, kişi, bunları ya kendisi dışında herkesten gizli yaşar, ya da bunları, kendisine çok güvendiği belirli kişilerle paylaşır (Kılıçoğlu, 2008:113). Prosser'a göre özel hayat ihlalleri dört başlıkta incelenir (Karahisar, 2011: 602):

a-Kişinin mahremiyetine karışma: Örneğin kişiyi gözetlemek ya da izni olmaksızın konutuna girerek yalnızlığını ihlal etmek

b-Etik kurallar dikkate alınmaksızın kişinin özel hayatına ilişkin durumları açı̆̆a vurmak

c-Kişinin izni olmaksızın isminin kullanmak

d-Bireyin kişiliğini oluşturan bazı unsurlarını (ses, görüntü vs.) ticari amaçli kullanma 
Özel hayata saygı hakkını, 'kişinin özel hayatının meşru olmayan müdahalelerden uzak tutulması konusunda hukuk düzeni tarafından korunmaya değer görülen bir yararının varlığının tanınması' şeklinde tanımlamak mümkündür. Özel hayata saygı hakkının 'gizlilik' ve 'bağımsızlık' olarak iki unsurunun bulunduğu kabul edilmektedir. Özel hayata sayg1 hakkı ile bireylerin özel hayat olaylarının hür iradelerine göre şekillendirilebilmeleri ve bunları istemedikleri üçüncü kişilerin öğrenmesini engelleyebilmeleri, sağlanmaya çalışılmaktadır. Özel hayata saygı hakkı, günümüzde geniş olarak yorumlanan kapsamıyla, kişi özgürlüğü, düşünce ve anlatım özgürlüğü, katılım ve çoğulculuk, maddi ve manevi varlığı geliştirme gibi hak ve özgürlüklerle yakın ilişki içerisinde değerlendirilmektedir (Keklik, 2012: 28-30).

\section{2. Özel Hayatın Gizliliğinin Korunması}

Özel hayatın gizliliği ve korunması, Anayasa ile güvence altına alınmıştır. Anayasanın 20. maddesine göre; 'Herkes, özel hayatına ve aile hayatına saygı gösterilmesini isteme hakkına sahiptir. Özel hayatın ve aile hayatının gizliliğine dokunulamaz. Milli güvenlik, kamu düzeni, suç işlenmesinin önlenmesi, genel sağlık ve genel ahlakın korunması veya başkalarının hak ve özgürlüklerinin korunması sebeplerinden biri veya birkaçına bağlı olarak usulüne göre verilmiş hâkim kararı olmadıkça; yine bu sebeplere bağlı olarak gecikmesinde sakınca bulunan hallerde de kanunla yetkili kılınmış merciin yazılı emri bulunmadıkça; kimsenin üstü, özel kağıtları ve eşyası aranamaz ve bunlara el konulamaz. Yetkili merciin kararı yirmi dört saat içinde görevli hâkimin onayına sunulur. Hâkim, kararını el koymadan itibaren kırk sekiz saat içinde açıkla; aksi halde, el koyma kendiliğinden kalkar' (Anayasa, 2013: 21-22). Özel hayatın gizliliğinin korunması hakkı, uluslararası bildiri, sözleşme ve belgelerde de güvence altına alınmıştır. $\mathrm{Bu}$ durum, özel hayatın gizliliğinin korunmasının, uluslararası ve ulusalüstü alanda önemli ve korunmaya değer bir hak olarak algılandığ gerçeğini göz önüne serer. İnsan Hakları Evrensel Bildirisi (BM)'nin 12. maddesinde, Medeni ve Siyasi Haklar Sözleşmesinin 17. maddesinde, Avrupa Konseyi İnsan Hakları Sözleşmesi'nin 8. maddesinde, Avrupa Birliği Temel Haklar ve Özgürlükler Bildirisi'nin 6. maddesinde, Temel Haklar Şartı'nın 7 ve 8. maddesinde, Avrupa Anayasa'nın 9. maddesinde, Amerikan Devletleri Örgütü-Amerikan İnsan Hakları ve Ödevleri Bildirisi 5. maddesi, Amerikan İnsan Hakları Sözleşmesi 11. maddesinde, Avrupa Güvenlik ve İşbirliği Teşkilatı İnsan Boyutu Konferansı'nın 24. maddesinde özel hayat hakkının düzenlendiği önde gelen temel uluslararası hükümlerdir (Sevimli, 2006: 23-24). Bunun yanı sıra birçok uluslararası anlaşmalarda özel hayat hakkına dair düzenlemeler bulunmaktadır.

Özel hayatın gizliliğinin korunması ile kişinin ve manevi varlığının korunması ve geliştirilmesi, bu sayede gerçek bir özgürlüğün sağlanması, hedeflenmektedir. Sosyal hayatın sık1 kurallara bağlı yapısı dikkate alındığında, kişinin özel hayatındaki hareket serbestisinin kendi kişisel varlığını geliştirmesi ve dolayısıyla insanlığın seviye kazanması için ne kadar önemli olduğu anlaşılır. Nitekim doğruya veya gerçeğe ulaşabilmek için özgür ve eşit bir tartışma ortamının gerekli olduğu ve bunun ancak özel hayatın gizliliğinin korunması ile sağlanabileceği, bu yönüyle özel hayatın gizliliğinin ifade özgürlüğü kadar önemli olduğu belirtilmiştir (Keklik, 2012: 68-69).

\section{Sonuç}

Anayasa Mahkemesinin 31.3.1987 gün ve E: 1986/24, K: 1987/8 sayılı kararı özel hayatın gizliliği ve korunması konusundadır. Bu kararda Anayasa Mahkemesi özel hayatın gizliliği ve korunması hakkını kişilik hakkının bir devamı saymıştır. Kararın ilgili bölümü şu şekildedir: "Özel hayatın korunması her şeyden önce bu hayatın gizliliğinin korunması, başkalarının gözleri önüne serilmemesi demektir. Orada cereyan edenlerin yalnız kendisi veya kendisinin bilmesini istediği kimseler tarafından bilinmesini istemek hakkı, kişinin temel haklarından biridir. Bu niteliği sebebiyledir ki, özel hayatın gizliliğine dokunulmaması, insan haklarına ilişkin beyanname ve sözleşmelerde korunması istenilmiş, ayrıca tüm demokratik ülke mevzuatında açıkça belirlenen istisnalar dışında bu hak devlet organlarına, topluma ve diğer kişilere karşı korunmuştur. İnsanın mutluluğu için büyük önemi olan özel hayata saygı gösterilmesi hakkı onun kişiliği için temel bir hak olup yeteri kadar korunmadığı takdirde kişilerin ve dolayısıyla toplumun kendini huzurlu hissedip güven içinde yaşaması mümkün değildir. $\mathrm{Bu}$ nedenlerle söz konusu gizliliği çeşitli biçimde ihlal eylemleri suç sayılarak ceza yaptırımlarına bağlanmıştır".

Sonuç olarak, özel hayat hakkı kişinin özel hayatını her türlü müdahaleden uzak ve özgürce yaşama hakkıdır. Özel hayata müdahale, bir hukuki gerekçeye dayandırılmadıkça hukuka aykırıdır. İnsan sosyal bir varlıktır ve toplumsal yaşamda da hakları vardır. Özel hayat, sadece kişinin özel yaşam alanıyla sınırlı değildir. Toplumsal yaşamdaki düşünce, ifade, din ve vicdan özgürlükleri bu kapsamdadır. Özel hayat hakkına verilen önem, temel insan hakkıdır ve ulusal/uluslararası alanda da yasalarla ve sözleşmelerle güvence altına alınmıştır.

\section{Kaynakça}

Akyürek, Güçlü (2011). Özel Hayatın Gizliliğini İhlal Suçları, Çeşitli Hukuk Dallarında Özel Hayatın Gizliliğinin Korunması, Seçkin Yayıncılık, Ankara.

Aras, Ümit Yaşar (2010). İnsan Hakları Temelinde Özel Hayat Hakkının Ulusal ve Uluslararası Alanda Uygulamaları, Bahçeşehir Üniversitesi Sosyal Bilimler Enstitüsü, Yüksek Lisans Tezi.

Doyle, Carolin- Bagarıc, Mirko (2007). "Mahremiyet Hakkı: Cazip Ama Kusurlu”, Özel Yaşam, Medya ve Ceza Hukuku, Karşılaştırmalı Güncel Ceza Hukuku Serisi: 7, Seçkin Yayıncılık, s.91-131, Ankara.

İşçibaş1, Yaprak (2011). "Televizyon Haberciliğinde Etik Bağlamında Özel Yaşam Kavramı”, 11. Medya ve Etik Sempozyumu, Medya-Kültür İlişsisinde Etik, s.165-172, Elazı̆̆.

Karahisar, Tüba (2011). "Özel Hayatın Gizliliği ve İnternette İşlenen Suçlar", $\quad$ II. Medya ve Etik Sempozyumu, Medya-Kültür İlişkisinde Etik, s. 599-606, Elazığ.

Keklik, Ramazan (2012). Özel Hayatın Gizliliğini İhlal Suçları, Adalet Yayınevi, Ankara.

Kılıçoğlu, M. Ahmet (2008). Şeref, Haysiyet ve Özel Yaşama Basın Yoluyla Saldırılardan Hukuksal Sorumluluk, Turhan Kitabevi, Ankara.

Kumcuoğlu, İpek (2011). "Mahremiyet mi, Kamu Çıkarı mı? Değişen Gazetecilik Kodları, Wikileaks ve Medya", 1l. Medya ve Etik Sempozyumu, Medya-Kültür İlişkisinde Etik, s.55-61, Elazığ.

Sevimli, K. Ahmet (2006). İşçinin Özel Yaşamına Müdahalenin Sınırları, Legal Yayıncılık, İstanbul.

Şen, Ersan (1996). Özel Hayatın Gizliliği ve Korunması, Devlet ve Kitle İletişim Araçları Karşısında, Kazancı Hukuk Yayınları, No: 48, İSTANBUL

Uğur, Selen (2013). "Sosyal Medya ve Gizlilik", Güncel Hukuk Dergisi, Ağustos 2013/8-116, İstanbul. TCK M.134 
Anayasa TCK-CMK ve İnfaz Kanunu (2013). 'Özel Hayatın

Gizliliği ve Korunması', Madde 20-21-22, s.21-23, Seçkin

Yayıncılık, Ankara.

TDK (2005). Türk Dil Kurumu Türkçe Sözlüğü, Ankara. 